\title{
Aspectos Formativos da Criação Artística: uma análise das imagens de revista de $V_{i k}$ Muniz
}

Formative Aspects of Artistic Creation: An ANAlysis of PiCtures of MAGAZINES OF VIK MUNIZ

Thais Priscilla Papa Jerônimo Duarte*

Resumo: Pensar os processos de criação como sistemas formativos é concebê-los por meio das diferentes relações que um artista estabelece durante o processo. No presente artigo, embasados pelas teorias da crítica genética, identificamos aspectos formativos que podem ser compreendidos como as conexões da rede da criação, onde cada componente do sistema passa a estabelecer influência sobre o outro, não em termos hierárquicos, mas de correlação. O entendimento desses movimentos, nem sempre com registros materiais disponíveis, só é possível a partir do momento em que a obra é interpretada como o resultado do acesso do artista a fontes diversas e heterogêneas. Para demonstrar a aplicação do conceito, apresentaremos a análise do processo de criação do artista plástico Vik Muniz na série "Imagens de Revista". Buscamos descrever sistemas formativos da obra, evidenciar gatilhos e identificar influências, fundamentais para que haja coerência nos registros. Demonstramos que, além de manuscritos, é possível recolher outros documentos de processo, desde que se estabeleçam critérios de análise que comprovem a veracidade e a constância das informações. Os registros analisados foram encontrados em diferentes fontes de pesquisa, mas remetem, sobretudo, ao conceito da própria obra como registro de processo.

Palavras-chave: Aspectos formativos. Processo criativo. Vik Muniz.

\footnotetext{
* Doutora em Estudos da Linguagem pela Universidade Estadual de Londrina (UEL). Professora na Faculdade do Norte Novo de Apucarana - Facnopar. Contato: thaisjeronimo@hotmail.com.
} 
Abstract: Think about the processes of creation as formative systems is conceive them by means of the various relationships that an artist establishes during the process. In this article, supported by the theories of genetic criticism, we identified formative aspects that can be understood as network connections of creation, where each component of the system is to establish influence over the other, not in terms of the hierarchy, but of correlation. The understanding of these movements, not always with records available materials, is only possible from the moment in which the work is interpreted as the result of access of the artist to various sources and heterogeneous. To demonstrate the application of the concept, we present the analysis of the process of creation of the artist Vik Muniz in the series "Pictures of Magazine". We describe formative systems of work, highlighting triggers and identify influences, fundamental to ensure consistency in the records. We demonstrate that, in addition to the manuscripts, it is possible to collect other documents of procedure, provided that the establishment of criteria for analysis proving the veracity and the consistency of information. The records were found in different sources for research, but they refer, in particular, the concept of the work itself as a record of proceedings.

Keywords: Formative aspects. Creative process. Vik Muniz.

\section{Introdução}

O olhar sobre o processo, o vir a ser, o movimento criador, os caminhos trilhados pelo artista até que a obra possa ser apresentada ao público, não só como um produto acabado, mas aberto a traduções. Eis os horizontes dos estudos genéticos, em constantes evoluções, rompendo fronteiras a fim de melhor compreender os processos de criação, nas mais diversas linguagens, inclusive nas obras de arte.

Como um dos frutos primogênitos da humanidade, a obra de arte recusa-se a ser interpretada como um sistema fechado, logo, é mais coerente interpretá-la por meio de um processo, englobando, inclusive, seu vir a ser. Analisar obras de arte é analisar imagens produzidas pelo homem, simples ou complexas, carregadas de intenções, sentimentos e sentidos. 
O fazer artístico não depende de normas preexistentes, ao contrário, é um processo, muitas vezes, imprevisível. Ao iniciar-se o trabalho, o artista tem diante de si um projeto e uma matéria. A obra que está sendo realizada segue sua lei interior, de tal modo que o resultado dificilmente pode ser previsto.

Estudar um texto, uma obra de arte, ou qualquer fruto da criação humana por meio da crítica genética é admitir que, além do produto final acabado, houve um processo de construção da obra. Tal perspectiva de processo amplia a compreensão da criação e revela os caminhos seguidos pelo autor, suas incertezas, mudanças de foco e decisões. Nesse contexto, estudamos o processo criativo do artista plástico brasileiro Vik Muniz (1961-atual).

A produção de Vik Muniz evoca o experimental. São fragmentos, codependentes, que apontam para a complexidade de uma estrutura maior, indicando uma obra aberta, onde a direção está ligada a questões que emergem durante o próprio processo de construção. No trabalho do artista, uma obra leva à outra, de forma até instintiva. Durante a criação das obras ocorre uma retroalimentação, de modo que mutações estruturais podem ser observadas, a começar pela evolução técnica.

Ao apropriar-se, ludicamente, de ícones, traduzindo-os por meio de materiais inusitados, as imagens de Vik desafiam o olhar. Por meio de experimentações, o artista cria e recria obras de arte que, posteriormente, são fotografadas e apresentadas ao público. Além da necessidade de servir de palco para as obras, a escolha pela fotografia contribui também para a aproximação do público. Neutralizados por ela, os materiais apresentam-se como pigmentos compondo a imagem de um quadro. Após uma primeira interpretação, quase literal, dos elementos presentes na própria fotografia, a apreciação da obra ativa o repertório do observador, estimulando novas possibilidades de leitura.

\section{Processos de Criação e Estudos Genéticos}

Após publicar o texto "Le texte n'existe pas", Louis Hay abriu sutilmente as portas do mundo sagrado dos manuscritos, fornecendo perspectivas de abordagens que transformam um objeto de culto em um 
objeto de sedução. A crítica genética reformula o objeto, materialmente idêntico ao da crítica textual, por meio de uma metodologia inovadora, rejeitando a rigidez dos princípios do modelo filológico:

Os pressupostos teóricos a partir dos quais a crítica genética se tem desenvolvido são outros: resultam de uma profunda reflexão que, embora tomando como referência Poe, Valéry, as propostas dos Formalistas Russos, num primeiro momento se afirmou em ruptura com o estruturalismo; e, no pós-estruturalismo, foi reforçando o diálogo com diversas áreas das ciências humanas e com diversas correntes do pensamento crítico, até o momento presente, em que se impõe como uma abordagem autônoma do fenômeno literário, a qual privilegia a vertente da criação - o ato de produção (REYNAUD, 1993, p. 231).

No Brasil, os estudos envolvendo crítica genética tiveram início na década de 1980. Em 1985, Philippe Willemart organizou o I Colóquio de Crítica Textual: o Manuscrito Moderno e as Edições, na Universidade de São Paulo, introduzindo a crítica genética no Brasil. No mesmo ano foi fundada a Associação dos Pesquisadores do Manuscrito Literário (APML) ${ }^{1}$. $\mathrm{Na}$ década de 1990, os estudos genéticos ganharam novos contornos, principalmente com as pesquisas desenvolvidas pelo Centro de Estudos Genéticos da PUC/SP², coordenadas por Cecilia Almeida Salles.

Willemart (2009, p. 57) esclarece que “o foco da crítica genética não se encontra necessariamente no estudo dos manuscritos ou dos esboços", ainda que tais materialidades tenham iniciado sua trajetória. "A crítica genética é também possível com textos dos séculos XVI a XVIII, sem manuscritos e com a produção eletrônica”. Tais afirmações se justificam pelo fato de que a crítica genética estuda processos de criação, o que, para Willemart, "é melhor com manuscritos, mas possível também sem eles".

${ }^{1}$ Atualmente Associação dos Pesquisadores em Crítica Genética. Disponível em: $<$ http://bit.do/dDyzk $>$.

2 Atualmente Grupo de Pesquisa em Processos de Criação (GPC). Disponível em: $<$ http://bit.do/dDyzu>. 
Reflexões sobre princípios fundamentais da disciplina abriram espaço para a ação transdisciplinar da crítica genética, confirmado, nas últimas décadas, com a ampliação do número de pesquisadores e de abordagens teóricas utilizadas. A perspectiva transdisciplinar, e a própria "vocação transartística", descrita por Ferrer (2002), possibilitaram o estudo do processo criador em outras manifestações artísticas. "Esse novo olhar implica, se não uma escolha, pelo menos prioridades: as da produção sobre o produto, da escrita sobre o escrito, da textualização sobre o texto, do múltiplo sobre o único, do possível sobre o finito" (GRÉSILLON, 2002, p. 147).

A análise genético-filológica abrange os momentos da reconstituição genética, o percurso trilhado pela obra até ser considerada "pronta". Hay (2007, p. 98) descreve que “o procedimento é muito simples em seu princípio: trata-se de compreender uma obra através de seu devir e não apenas por seu resultado”. A crítica genética surge justamente do desejo de compreender melhor a criação artística, a partir dos registros do percurso do artista. Buscase um entendimento mais aprofundado da obra e do respectivo processo no instante de produção, trata-se da comprovação do trabalho resultante de um processo criativo.

O objeto primordial de estudo da crítica genética parte de onde nasce o movimento da gênese, permitindo que diversos componentes do ato criador, bem como suas relações, sejam deflagrados. Ao longo do processo, há uma efetivação de registros que raramente podem ser identificados na obra exposta ao público. Em seu trabalho de pesquisa, o crítico passa a conviver com o ambiente do fazer artístico, sendo conduzido pelo universo do artista.

Com raras exceções, a obra de arte é o resultado de um trabalho que se caracteriza por transformação progressiva, que exige, por parte do artista, investimento de tempo, dedicação e disciplina. Na obra, é possível identificar um condensamento das estruturas fractais que a constituíram. A concretização do processo de contínua metamorfose é evidenciada por meio dos rastros deixados pelo artista. Tal metamorfose é entendida por Ostrower (2010, p. 51) no sentido de que "tornar importa em transformar".

Todo processo de elaboração e desenvolvimento abrange um processo dinâmico de transformação, em que a matéria, que orienta a ação criativa, é transformada pela mesma ação. Transformando-se, a matéria não é destituída 
de seu caráter, mas diferenciada e definida como um modo de ser, adquirindo unicidade e reafirmando sua essência. Ela se torna matéria configurada e, nesta síntese entre o geral e o único, é impregnada de significações.

$\mathrm{O}$ artista medita sobre a obra que será executada como se fosse um alvo a ser atingido. No momento em que a obra se concretiza, o pensamento estético faz-se visível. A partir dos rastros do processo, a crítica genética define os atos de produção. Para Neefs (1994), os registros de obras nos indicam, muito à frente de si, o mundo da virtualidade estética. Os vestígios deixados pelo artista denunciam o funcionamento do pensamento criativo e a repetição de gestos permite que teorias sobre o ato criador sejam deflagradas.

Segundo Le Men (2004, p. 11), “a abordagem genética introduz uma temporalidade na obra de arte”. Como indica sua etimologia, a palavra 'genética' significa tanto 'tornar-se' como 'ser'. Dessa forma, o crítico genético estuda a obra de arte no gerúndio, o trabalho que está sendo feito, ao invés de congelado em um único momento, o que, consequentemente, induz a uma definição mais ampla da obra de arte. Um pensamento em construção pode ser evidenciado quando analisamos a relação entre os registros deixados pelo autor e a obra entregue ao público. Os registros podem ser considerados como extensões do pensamento do artista, desta forma, a partir da relação entre dados e obra, o crítico passa a reconhecer o percurso criador.

Ao descrever o processo de criação artística, Neefs (1994) aponta euforias e frustrações, características do trabalho. Afirma que a aventura da realização de um projeto apresenta padrões heterogêneos. A ideia do artista se metamorfoseia por meio de temas, formas, cores e estruturas, buscando uma nova disposição estética. Durante o processo de construção da obra, o artista põe à prova diversas hipóteses, realizando seleções e efetivando testagens que, normalmente, revelam novas formas e configuram novas realidades. A luta com as limitações da matéria a fim de transformá-la faz com que, durante o processo, o artista veja a obra como autossuficiente, causando dúvidas, confusões e indecisões.

Neefs (1994) descreve ainda que a ânsia e a necessidade de atingir a intensidade almejada e uma estética para conquistar impedem o artista de parar. Os movimentos de ir e vir das mãos criadoras são direcionados por projeções que invadem o espaço de trabalho, como um imperativo para a 
execução. Neste momento, a tensão do trabalho do artista torna-se sua consistência e sua verificação. Sobre a tensão do movimento criador, Salles (1998, p. 63) descreve que o processo dá-se na relação entre a tendência e a mobilidade do percurso que está inserido no fluxo de continuidade. A tensão entre projeto e processo deixa aparente o ato criador como um "projeto em processo". Estudar os rascunhos permite ao pesquisador invadir a imaginação do autor - no caso das obras de arte, o artista - e perceber ênfases por meio de marcas deixadas durante o processo, enfim, perceber os recursos utilizados para dar forma à mensagem que será veiculada:

Na sua vida de pulsões e desejo, o escritor, para não dizer o artista em geral, particularmente sensível à tradição cultural e ao mundo em que vive, retém de forma singular informações do passado e do presente. Os elementos detidos nesse filtro particular, formam um entrelaçamento ou nó, que de certo modo bloqueia o desejo do artista e o incomoda. Desse bloqueio ou dessa barreira nascem o primeiro texto e o autor (WILLEMART, 1993, p. 92).

Willemart (1993, p. 92) descreve ainda uma "lenta aglutinação de elementos", característica de um processo que não nasce pronto, mas vai se revelando após períodos de reflexão do próprio artista. Daí a importância de se respeitar o tempo de concepção e execução do produto considerado final pela mão criadora. Entendemos a gênese como uma decantação de referências e de perspectivas. Após um processo de acumulação de estratos, o resultado final do processo, apresentado ao público, representa somente uma das camadas visíveis.

Tais características e, logo, a necessidade de compreensão por parte do crítico, fundamentam-se nas próprias fases da criatividade. Kneller (1978, p. 62) afirma que durante o processo criador há quatro fases reconhecíveis: "preparação, incubação, iluminação e verificação". Além de apresentar as fases do ciclo criador, o autor reconhece que a criação requer técnica e que, para realizar uma ideia, o artista necessita dominar os meios para exprimi-la. Para desenvolver a técnica, é necessário acumular competências relacionadas à materialidade e ao projeto que será executado. Para Panichi e Contani (2003, p. 9), a competência é um conjunto de habilidades que para ela convergem, logo, é necessário construí-las, permanentemente. Os autores 
afirmam que "coletar idéias adequadas à análise do objeto de estudo constitui um desses procedimentos".

Para Le Men (2004, p. 14), estudar uma obra de arte no gerúndio é romper com o receio do inacabamento, pelo contrário, é denunciar a ilusão do acabado e vislumbrar o processo de criação em sua incompletude perpétua. Entender o tempo da criação é entender a própria configuração poética do projeto. Durante o desenvolvimento o artista buscará a tradução perfeita da imagem que será revelada ao público, por meio de uma reprodução específica, ou seja, o meio fornecerá a forma. Ainda discutindo a reprodução, Le Men (2004, p. 10) expõe que é possível comparar, de forma equivalente, o trabalho inaugural de um artista a exemplos de incipit literários ou frontispícios.

O término, a divulgação do trabalho, seja talvez o momento decisivo para o artista. Quando e como considerar uma obra acabada? Galeffi (1977, p. 22) busca responder a essas questões afirmando que os resultados da obra serão sempre homologados pela sua própria sensibilidade estética, "quando esta julgue e aceite aqueles resultados como uma fonte de harmonia ou de encantamento ou de emoção estética" para o próprio artista e para possíveis observadores da obra.

O crítico genético toma a obra, assim como foi entregue ao público, como uma referência para estabelecer o "ponto final". A obra é a representação mais próxima daquilo que o artista buscava naquele processo; "daí a obra ser usada como ponto de referência para o acompanhamento das decisões do artista ao longo do percurso" (SALLES, 2000, p. 57).

O entendimento do percurso criativo, suas idas e vindas, só será compreendido plenamente por meio dos arquivos de criação. Diante da evolução dos objetos de estudos é fundamental retomar um conceito, já postulado por Hay (2007), de escritura em processo, e repensá-lo no universo das obras de arte. Uma perspectiva que compreenda os objetos artísticos como frutos de um sistema de interações, em constantemente transformação. Tal perspectiva molda novas metodologias para acompanhamento dos processos construtivos da arte contemporânea.

As próprias características das obras exigem uma evolução de pensamento da construção em redes, amplamente discutido por Gilles 
Deleuze, nos conceitos de rizoma ${ }^{3}$ e princípios rizomáticos. Há duas dimensões distintas para compreensão do conceito, uma imagética, relacionada ao modelo oriundo da biologia, e uma conceitual, voltada à ideia de redes, onde o processo de criação das obras é discutido como um sistema conceitual aberto. Deleuze e Guattari (1995, p. 28) postulam os "sistemas como centros de significância e de subjetivação, autômatos centrais como memórias organizadas".

Assim como a crítica genética possui características transdisciplinares, o conceito de rizoma também assim se manifesta, a própria transdisciplinaridade é rizomática. A partir do material estudado, o crítico passa a refazer e compreender a rede de relações estabelecida pelo artista. Os movimentos apresentam características de simultaneidade de ações, ausência de hierarquia, não linearidade, dinamicidade e intenso estabelecimento de nexos. Não designam, necessariamente, correlação ou reciprocidade, mas movimentos transversais. O conceito de transdisciplinaridade é polissêmico, evocando a ideia de ultrapassar limites.

Pautados por esses direcionamentos, adotando a noção de processo e compreendendo o processo de criação como um emaranhado de linhas conectadas, onde não se distingue início ou fim, sendo cada linha responsável por seu próprio devir, é que desenvolvemos nossas investigações e reflexões sobre os aspectos formativos da obra de Vik Muniz. Para as análises, efetuadas no presente estudo, lançamos mão de teorias relacionadas aos domínios da imagem, da fotografia, do universo das obras de arte, da semiótica, da estética, da fenomenologia e, sobretudo, dos processos de criação artísticos.

\section{Referências do Processo Criativo}

Os arquivos genéticos nos remetem a eventos que revelam tentativas e reservas, experiências e propostas de progresso, além das expectativas do

${ }^{3}$ O conceito de rizoma foi cunhado por Deleuze em 1976 (DELEUZE, G. Rizhome. Paris: Les Éditions de Minuits, 1976). Posteriormente, Deleuze e Guattari (1995) aprofundaram conceitos, noções e práticas, visando o estabelecimento de um pensamento não linear, sem hierarquia definida e com multiplicidade de conexões, descrevendo um processo de construção em rede, aplicável a diferentes áreas do conhecimento. 
artista, vetores de um desenvolvimento criativo ao mesmo tempo atraente e desconhecido. O estudo do processo de criação promove o confronto de uma obra com todas as possibilidades que a compõem, tanto a questões anteriores, quanto posteriores a ela. A obra envolve uma rede complexa de acontecimentos. Esse processo de transformações contínuas é concretizado pelos rastros deixados pelo autor: por esse motivo, o ato criativo fascina receptores e criadores.

Em seu processo de apreensão do mundo, o artista estabelece nexos inovadores. Para Salles (2000, p. 94-95), a transformação se dá por meio de combinações insólitas que acontecem na complexidade dos meandros da percepção artística. "Encontramos, assim, a unicidade de cada obra e a singularidade de cada artista na natureza dessas combinações e no modo como essas são concretizadas".

Apesar de espontâneo, há mais do que certa consciência no combinar, no associar, há coerência. Ostrower (2010, p. 21) descreve que, “embora as associações nos venham com tanta insistência, que talvez possam tender para o difuso, são estabelecidas determinadas combinações, interligando-se ideias e sentimentos". Em termos materiais, o objeto manuseado pelo crítico genético é limitado, contudo, é ilimitado em sua potencialidade interpretativa. Apesar do aparente domínio sobre a obra, por vezes, a mente do criador é tomada por questionamentos quanto aos próximos passos, o que acrescentar ou subtrair:

Num tipo de busca que integra variadas formas de ser, o criador defronta-se com fatos reais, fatores de elaboração do trabalho que tornam possível optar e decidir por uma ou outra, numa atitude de tomar decisão e atuar. Não se trata de um processo de mão única em que um pensamento pode ser colocado de imediato em sua forma definitiva. Há uma seqüência de transformações, daí a pertinência de afirmar o contínuo processo de tradução (PANICHI; CONTANI, 2003, p. 103).

A experimentação é um recurso do processo de transformação. A partir dos materiais coletados e armazenados, o artista possui um universo mais "palpável" de relações que poderão ser efetuadas. Os exercícios de 
exemplificação e da materialização de um conceito ficam mais fáceis de serem aplicados. Partindo de um mesmo material de apoio, diferentes obras podem ser criadas, de acordo com a especialização e a intenção de cada artista.

Para Eco (1972, p. 227), a partir do momento em que uma situação de experimentação se transforma em um "ato de interrogação do material novo para lhe perscrutar as possibilidades de organização, de formação que lhe sugere, reencontramos a dialética da produção artística". O processo de experimentação, segundo Salles (1998, p. 153), deve ser analisado pela perspectiva de movimento e não necessariamente como uma evolução: "Nas idas e vindas do processo, assistimos a muitas recuperações de formas negadas". Não há segurança por parte do criador de que o novo caminho trará resultados melhores do que os anteriores.

A experimentação pode ser compreendida como um campo de testagem, que revela a natureza investigativa do processo criador. $\mathrm{O}$ que atribui unicidade ao trabalho de cada artista é, justamente, o modo como efetua as testagens, avalia a materialidade e define novos rumos por meio de escolhas que passam a traduzir suas percepções. Decisões e hesitações são características da ação do artista, envolvem avaliações e escolhas que revelam as intenções da mão criadora.

Cada materialidade abrange, de início, certas possibilidades de ação e outras tantas impossibilidades. Se as vemos como limitadoras para o curso criador, devem ser reconhecidas também como orientadoras, pois dentro das delimitações, através delas, é que surgem sugestões para se prosseguir um trabalho e mesmo para se ampliá-lo em direções novas (OSTROWER, 2010, p. 32).

A imaginação criativa levanta hipóteses sobre certas configurações viáveis a determinada materialidade. Assim, segundo Ostrower (2010, p. 32), "o imaginar seria um pensar específico sobre um fazer concreto". Durante o processo, o artista lança mão de recursos a fim de que o projeto seja viabilizado.

O material é um recurso fundamental da diferenciação das artes. A escolha de um novo material, por vezes, é capaz de originar uma nova arte 
ou estilo. Por meio da experimentação de materiais inusitados, Vik cria e recria obras de arte que, posteriormente, são fotografadas e apresentadas ao público. Explora, propositalmente, um caráter híbrido e ambíguo da imagem. Enfatiza o diálogo entre o material, objetos simples que usa para fazer as composições, e a imagem.

A experimentação de materiais pouco convencionais é influência da Arte Pop, ou Pop Art, movimento de arte visual surgido no final da década de 1950, na Inglaterra e nos Estados Unidos. A busca pela valorização da cultura popular era retratada nos objetos usados para fazer arte: enlatados, produtos descartáveis, látex, enfim, produtos relacionados ao universo do consumo. As técnicas buscavam a intersecção de diferentes formas de arte, como a pintura, a fotografia, as colagens e a escultura.

A obra de Vik faz com que o espectador questione a imagem a partir das camadas de significados. A fim de melhor compreender tal aspecto do processo criativo, buscamos compreender as redes criativas percorridas durante a concepção da obra, demonstrando aspectos fundamentais de sua gênese.

\section{Aspectos Formativos das Redes de Criação}

Como fenômeno social, a arte possui relações com a sociedade. Elas não são estáticas e imutáveis, ao contrário, são dinâmicas, modificando-se historicamente. $\mathrm{O}$ artista é um ser social, à medida que se apoia numa determinada concepção do mundo, passa a exprimir, por meio dela, seu estilo. As interações são, muitas vezes, responsáveis por novas mudanças durante o processo, suscitando novos olhares para a obra em construção. Novas possibilidades são avaliadas e o artista pode efetuar seleções e estabelecer critérios de continuidade. Para Ostrower (2010, p. 102), “o contexto cultural orienta os rumos da criação no sentido de certos propósitos e certas hipóteses virem a se tornar possíveis".

O microcosmo no qual o artista está inserido imprime ao trabalho final uma gama de significados e de possíveis relações a serem estabelecidas. Dessa forma, reflexões sobre as possíveis interações do processo criativo, em determinado tempo e espaço, são fundamentais. Toda obra de arte é originária de um ato de escolha, uma qualidade estética intrínseca, expressada e comunicada pelo artista. 
Resgatando a origem da palavra tradução, do latim, traducere, “converter, mudar", a presença do conceito é nítida na obra de Vik Muniz. Entendida pela perspectiva de Panichi e Contani (2003, p. 139), a tradução, no universo dos estudos genéticos, é o princípio de "retirar de uma fonte antecedente significados implícitos que possam funcionar em complementação descobrindo, assim, novas realidades. Toda tradução requer uma nova informação estética". O artista entende que a cópia enquadra-se em um "modelo de criatividade não-revolucionário", carregado de novas informações estéticas:

A tradução se dá, geralmente, quando se sente uma relação de semelhança entre o original e o que se quer expressar. Traduz-se aquilo que toca, que sensibiliza, que provoca [...] Buscam-se traduzir as semelhanças não explícitas no original, instalando um desequilíbrio entre o estabelecido e o convencional e o resultado da operação criativa. Como se pode perceber, tradução e criação se interpenetram (PANICHI; CONTANI, 2003, p. 143)

O original, selecionado para ser traduzido, por si mesmo já constitui um esboço da criação. Diferente de uma imagem que existe unicamente no imaginário do artista, a maior parte das imagens de Vik já possui uma configuração exógena, seu trabalho de criação consiste em selecionar o material ideal e a técnica que possibilitarão a transmutação das formas.

A história de cada obra é composta por todas as obras já realizadas e as que hão de ser feitas. A singularidade de cada projeto possibilita a produção de novas leituras e novas traduções. Para Neefs (1994), cada trabalho abre caminho para os outros, uma vez que o artista trabalha para implementar uma nova relação com o todo, composta pelo que já aconteceu. Por meio de um amplo movimento estratégico, capaz de configurar todo o trabalho, a interferência criativa é forjada entre o projeto e a descoberta, entre o imaginável e o desconhecido.

Analisando obras produzidas por Vik Muniz, ao longo dos vinte e cinco anos, é possível constatar que a própria obra do artista foi se revelando como um grande registro de sua criação. A recuperação de formas, de materiais ou de técnicas, em novas obras, fez com que assistíssemos à execução 
de possibilidades que foram deixadas de lado em séries anteriores. A interpretação desses fenômenos nos possibilitou identificar sistemas formativos das obras do artista, apontando aspectos singulares de sua gênese.

Indicar os aspectos formativos das obras abre portas para uma melhor interpretação do percurso seguido pelo artista. Para Salles (2002, p. 188), "todos os registros deixados pelo artista são importantes, na medida em que podem oferecer informações significativas sobre o ato criador". Contudo, a autora (2002, p. 185) reconhece que "há muito do movimento criador que não é registrado. São andamentos da obra que se mostram como resultado de trabalho mental".

No processo de criação artística, há uma tensão dialética entre o ambiente e o material, característicos de qualquer gênese. Para analisar as tensões entre os objetos e suas imagens, é preciso negociar a posição do objeto no tempo histórico e a posição do objeto em si, bem como a história de sua produção. A operação da gênese é caracterizada pela relação entre o meio e as ferramentas utilizadas pelo artista.

Pensar na criação como um complexo sistema é concebê-la por meio das redes de relações que o artista estabelece durante o processo. Os aspectos formativos podem ser compreendidos como as conexões da rede da criação, onde, cada componente do sistema passa a estabelecer influência sobre o outro, não em termos hierárquicos, mas de correlação. Panichi e Contani (2003) descrevem que a associação de elementos, a princípio díspares e contraditórios, entram em tensão durante a execução de uma obra, dependendo da forma como se conduzem as ideias do artista.

O entendimento desses movimentos só é possível a partir do momento em que a obra é interpretada por meio de um sistema formativo, compreendendo que as fontes acessadas por um artista são diversas e heterogêneas, e que cada aspecto contribui para que a obra se apresente da forma como é entregue ao público. Para Salles (2010, p. 120), “as interações da rede são responsáveis pela proliferação de novas possibilidades: ideias se expandem, percepções são exploradas, acasos e erros geram novas possibilidades de obras".

Entendemos os sistemas formativos da criação artística pela mesma perspectiva que Willemart (2002, p. 87) descreve os processos de escrita: “O estudioso do manuscrito não vai encontrar uma única lógica, mas um conjunto 
de lógicas acumuladas e entrelaçadas". Essa perspectiva reafirma a não linearidade da criação artística.

A criação da obra de arte é semelhante ao processo de escrita, também descrito por Neefs (1994). Ao escrever, o escritor desenha, no papel, uma imagem por ele formatada, obedecendo a uma mobilidade entre a imaginação e a linguagem, redistribuindo, constantemente, a imagem interior e o que está sendo construído. Pela configuração linear da língua, o escritor é forçado a listar, um após o outro, os componentes da paisagem por ele definida. O processo é permeado por escolhas constantes, por avaliações subjetivas, onde alguns termos são selecionados e outros preteridos. $\mathrm{O}$ artista avança e recua, progride e regressa, busca novas referências de acordo com as relações que estabelece no meio. Armazena, seleciona, escolhe, insere, retira, combina, segue o curso que a obra exige.

Conforme as fronteiras dos manuscritos literários foram rompidas e os estudos dos processos de criação estenderam-se a outras linguagens, fezse premente o desenvolvimento de novas metodologias para estudar os arquivos de criação, em suas diversas materialidades. As vias da criação passaram a ser descritas por meio de novos vestígios, de novos documentos de processo, de novas abordagens e análises. Willemart (2009, p. 7) descreve que a obra exposta, no caso da arte, possibilita que o crítico genético identifique "as fronteiras em que as peças do quebra-cabeça se encaixam", constatando "como se constrói a fractalidade".

Diante desse cenário, é fundamental pensar em uma transposição genética, utilizando abordagens que sejam específicas ao corpus estudado, contudo, valendo-se de conceitos de um domínio para outro. Biasi (2002, p. 219) atenta-se para a necessidade de descobrir métodos de estudo, válidos para o prototexto literário, que possam ser aplicáveis a outros objetos da cultura. Adaptações são indispensáveis a fim de que sejam estruturadas as mudanças necessárias para uma real transferência metodológica.

Ao abordar a questão da gênese das formas e o surgimento de imagens, devemos levar em conta uma série de temas que fluem, sob medida, para cada corpus analisado, bem como propostas metodológicas pertinentes aos documentos de processo. Apesar de fortes semelhanças, os estudos relacionados a artes plásticas parecem implicar numerosas características inexistentes no âmbito textual. 
Aplicar a metodologia de estudos genéticos a novos corpos é entendêla a partir de uma nova perspectiva, a de uma abordagem cognitiva que deverá "comparar diferentes aspectos mentais da atividade criativa, independentemente dos modos de enunciação". Tal abordagem deverá estar centrada na complexidade do processo de criação e na interpretação de imagens a partir de materiais genéticos heterogêneos (LE MEN, 2004, p. 12).

A autora afirma ainda que o caminho genético é alargado em favor de um longo processo que leva em conta o horizonte de expectativa e recepção de imagens, além da questão do autor, "no caso da libertação coletiva de um signo icônico", a própria imagem em si. A imagem possibilita a capacidade perceptiva do indivíduo. O resultado entre a simbiose do projeto original e da obra entregue ao público é muito mais rico do que a simples intenção do artista.

O projeto poético do artista é fundamentado nas trocas de informações com o meio onde está inserido. Ele cria em determinado tempo e espaço, a seu modo único e singular. Elementos interiores e exteriores ativam o pensamento criador. As conexões estabelecidas podem ser responsáveis pelo grau de inventividade ao longo do percurso. A partir do momento em que aceitamos o artista como um ser social, entendemos o processo de retroalimentação da obra com tudo que lhe é externo, validando seus aspectos formativos e comunicativos. Nesse sentido, buscando uma maior aproximação com o universo criativo, passamos a reconstruir a rede de relações estabelecidas pelo artista durante o processo criativo.

\section{Aspectos formativos das "Imagens de Revista"}

Vik Muniz reside, desde 1983, nos Estados Unidos, porém, o casamento com uma brasileira e o aumento do número de exposições no Brasil fez com que o artista passasse mais tempo no país e fixasse residência temporária no Rio de Janeiro. Nesse sentido, a convivência com brasileiros, especialmente no ambiente urbano do Rio de Janeiro, influenciou significativamente a produção de alguns de seus trabalhos. Segundo o próprio artista (MUNIZ, 
2007, p. 147), "não há lugar mais fácil para ser famoso por quinze minutos do que no Brasil", fenômeno construído pela mídia.

O ambiente exprime sua força, manifestando, na obra, características de determinado momento sócio-histórico. Conforme discutimos anteriormente, o ir e vir da mão criadora é, muitas vezes, caracterizado como uma rede dinâmica conduzida por tendências. O acompanhamento de processos de criação permite verificar como a efervescência cultural incita o artista. Ele observa o mundo e recolhe aquilo que, por algum motivo, o interessa. Trata-se de um percurso sensível e epistemológico de coleta: o artista recolhe aquilo que de alguma maneira toca sua sensibilidade. Esses armazenamentos funcionam como algo que futuramente será explorado, atuando como uma memória para as obras.

Nos períodos que passava no Rio de Janeiro, Vik tinha por costume frequentar, diariamente, bancas de jornal, adquirindo todas as publicações e armazenando-as. Quando passou a conhecer e conviver com as pessoas que só via, até então, estampadas nas capas de revistas, descreveu: "pode ser muito difícil casar a realidade com a versão da mídia: elas não parecem ser as mesmas. As conhecemos por meio de uma fonte fragmentada e editada" (MUNIZ, 2007, p. 147). Foi justamente a curiosidade em investigar a fragmentação do indivíduo pela mídia, somada ao armazenamento do material, que acabou motivando a série "Imagens de Revistas".

A escolha do material a ser utilizado é definitiva para possibilitar, ou não, a transmutação de uma imagem endógena para uma imagem exógena, ou seja, a imagem já construída pelo artista, em sua mente, para a imagem que irá produzir. Assim como na série "Crianças de Açúcar", de 1996, a opção pela utilização de revistas parecia óbvia. A motivação da série, seus objetivos e os materiais já armazenados acabaram por definir os rumos da criação.

Contudo, com relação à técnica a ser empregada, é possível observar diferentes referências, principalmente, de obras anteriores. Na série "Imagens de Buracos", de 1997, o artista utilizou um furador como ferramenta para criar confetes de papel branco. Na série "Filtros de Luz", de 1999, Vik utilizou, pela primeira vez, a técnica de vitrais, compondo rostos por meio de fragmentos. Já em 2002, na série intitulada "Imagens de Cor", trabalhou 
a multiplicidade das cores por meio de recortes de diferentes tons de Pantone ${ }^{\circledR}{ }^{4}$, compondo retratos e naturezas-mortas.

Apesar de pouco nítidas, as imagens são totalmente reconhecíveis. Como a série buscava retratar a fragmentação do indivíduo, Vik recorreu à ideia de "pixelização" presente nas imagens digitais, principalmente nas de baixa resolução. Finalizando as referências, até então catalogadas, apontamos outra influência presente no processo criativo da série, os retratos produzidos pelo artista Chuck Close ${ }^{5}$.

Em todas as séries é possível observar conceitos da Gestalt ${ }^{6}$, presença constante nas obras do artista, demonstrando, fundamentalmente, as relações entre as partes e o todo. Sendo a totalidade uma integração de suas partes, e não simplesmente uma adição, o todo constitui uma sintese que, no caso da criação artística, vem a ser a própria obra.

Entendendo a multiplicidade dos aspectos acionados pelo artista e buscando compreender melhor as relações existentes entre as principais referências utilizadas para a execução da série, procuramos ordená-las respeitando a não linearidade e a inexistência de hierarquia, compondo o sistema a seguir:

${ }^{4}$ A marca PANTONE® foi criada pela Pantone Inc. que está sediada em Carlstadt, Nova Jersey, EUA. O nome PANTONE® é conhecido mundialmente como a linguagem padrão para a comunicação em todas as fases do processo de gerenciamento de cores. Fonte: $<$ http://bit.do/dDyzy $>$.

${ }^{5}$ Fotógrafo e pintor americano. Utiliza técnicas em que a pintura é similar a uma fotografia, enquadrada no hiper-realismo.

${ }^{6}$ A Teoria da Gestalt foi elaborada por um grupo de pesquisadores da área da psicologia da percepção e tem como questão central o modo como se estruturam e reestruturam novas totalidades na percepção. Um de seus princípios básicos foi definido por Max Wertheimer: "O todo é mais do que a soma de suas partes". Gestalt, do alemão, significa: figura, configuração ou forma (GOMES FILHO, 2003). 


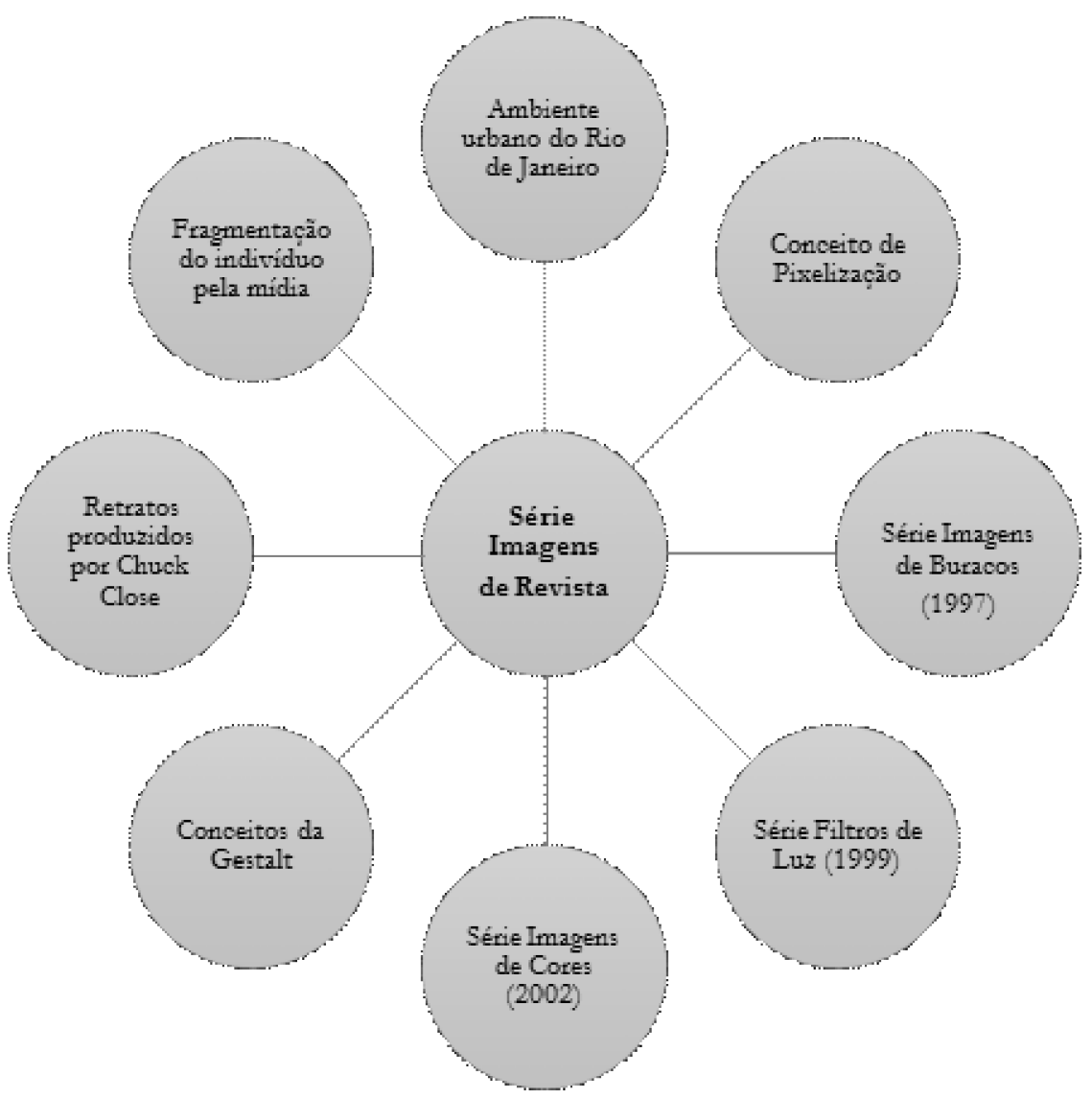

Fonte: Elaborado pela autora.

Figura 1 - Aspectos formativos - "Imagens de Revista"

As características de cada aspecto formativo do sistema são diversas. São fontes acessadas pelo artista em momentos distintos, que só puderam ser resgatadas e ordenadas a partir da análise do movimento criador. A disposição cíclica visa demonstrar o caráter complementar de cada componente, revelando um sistema autorreferencial. Daí a importância de se analisar a obra como um todo. Os registros analisados foram encontrados em diferentes fontes de pesquisa, mas remetem, sobretudo, ao conceito da própria obra como registro de processo. 
Movido pelo repertório descrito, Vik passou a fotografar artistas e pessoas comuns, e compôs cada uma das imagens utilizando confetes feitos de revistas, furados uniformemente. Um dos desafios da execução da série foi a necessidade de encontrar tonalidades de pele que caracterizassem as pessoas retratadas. O produto final foi fotografado e exposto em painéis de $233,70 \times 182,90 \mathrm{~cm}$, fazendo com que cada confete apresentasse o tamanho, aproximado, de uma bola de tênis.

$\mathrm{Na}$ série, o artista, intencionalmente, reproduziu pessoas famosas, estampadas nas capas das revistas, e ilustres desconhecidos. O propósito era demonstrar que, quando representado, o efeito de fragmentação culmina em resultados semelhantes, independente do indivíduo. Expostas lado a lado, Luciana, manicure das atrizes da Rede Globo, e Camila, atriz, compostas pelo mesmo material, apresentam-se em caráter de igualdade.
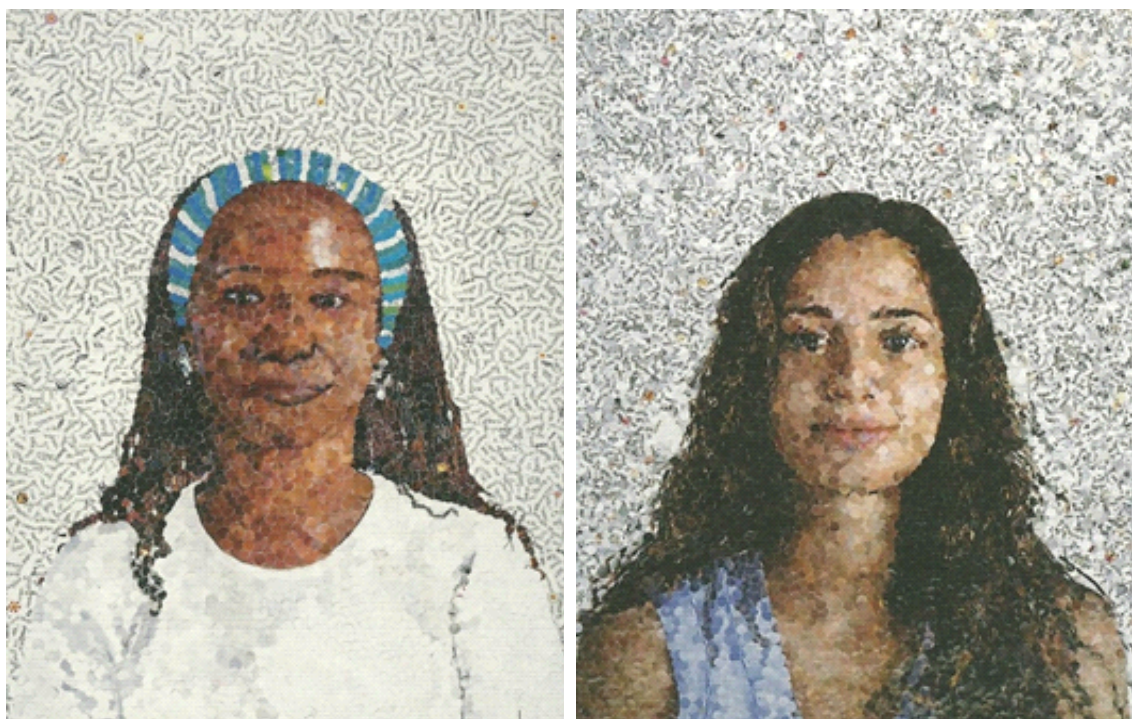

Fonte: Lago (2009, p. 490-491)

Figura 2 - "Luciana", à esquerda, e "Camila", à direita

Apesar da motivação inicial da série estar voltada à fragmentação do indivíduo, uma vez comprovada a versatilidade do material, Vik buscou 
empregá-lo na produção de imagens com características diferenciadas. O desdobramento da série produziu dezenas de novas imagens, indicando domínio da técnica e demonstrando a versatilidade do material.

\section{Conclusão}

Conduzidos pelos estudos genéticos, percorremos alguns caminhos trilhados por Vik Muniz para a criação de suas obras. A perspectiva de estudo da crítica genética nos permitiu conhecer os caminhos trilhados pelo artista durante o processo de concepção da obra. Sua metodologia nos deu suporte de trabalho para compilação da obra, análise de documentos de processo, criação de dossiê preliminar para recorte do corpus de pesquisa e confronto dos dados com a obra finalizada.

O movimento da criação, em si, deve ser sempre pensado por uma perspectiva de continuidade, sem demarcações de inícios ou fins absolutos. Porém, em um dado momento, a obra tem que ser dada como acabada, sendo entregue ao público. $\mathrm{O}$ artista será sempre tentado a manter o processo de criação ativo, contudo, enquanto a obra não for exposta, não terá cumprido seu papel social. Entendendo a característica do processo criativo de Vik Muniz, pudemos atestar que o artista julga uma obra finalizada no momento em que sela, com o suporte fotográfico, o resultado da criação.

O raciocínio da criação é outro, outro olhar precisa ser trabalhado, extrapolando os limites dos rascunhos. Demonstramos que é possível recolher outros tipos de documentos de processo, desde que se estabeleçam critérios de análise que comprovem a veracidade e a constância das informações, além da credibilidade de fontes e complementariedade dos materiais.

A repetição de ideias é necessária, e fundamental, para a validação das análises. Buscamos descrever sistemas formativos da obra, evidenciar gatilhos e identificar influências, fundamentais para que haja coerência nos registros. Enfim, defendemos que os documentos de processo, independente da materialidade, precisam ser vistos como uma trama, tecida a fim de contar a história do processo de criação. História que, uma vez deflagrada, proporcionará o real prazer da imagem, definido pela unicidade que configura o lado do qual a obra provém, contraposto pela multiplicidade à qual se dirige. 


\section{Referências}

BIASI, P.-M. de. O horizonte genético. In: ZULAR, R. (Org.). Criação em processo: ensaios de crítica genética. São Paulo: Iluminuras, 2002. p. 219-252.

DELEUZE, G.; GUATTARI, F. Mil platôs: capitalismo e esquizofrenia. Tradução Aurélio Guerra Neto e Célia Pinto Costa. Rio de Janeiro: Editora 34, 1995. v. 1.

ECO, U. A definição da arte. Lisboa: Edições 70, 1972.

FERRER, D. A crítica genética do século XXI será transdisciplinar, transartística e transemiótica ou não existirá. In: ZULAR, R. (Org). Criação em processo: ensaios de crítica genética. São Paulo: Iluminuras, 2002. p. 203-218.

GALEFFI, R. Fundamentos da criação artística. São Paulo: Melhoramentos; Editora da USP, 1977.

GOMES FILHO, J. Gestalt do objeto: leitura visual da forma. São Paulo: Escrivuras, 2003.

GRÉSILLON, A. Devagar: obras. In: ZULAR, R. (Org). Criação em processo: ensaios de crítica genética. São Paulo: Iluminuras, 2002. p. 147-176.

HAY, L. A literatura dos escritores: questões de crítica genética. Tradução Cleonice Paes Barreto Mourão. Belo Horizonte: Editora UFMG, 2007.

KNELLER, G. F. Arte e ciência da criatividade. 5. ed. Tradução J. Reis. São Paulo: IBRASA, 1978.

LAGO, P. C. do. (Org.). Vik Muniz: obra completa - 1989-2009. Rio de Janeio: Capivara, 2009.

LE MEN, S. Présentation - L'œuvre d'art en devenir. Chemins faisant... et «prés parés» Genesis, n. 24, p. 7-19, 2004.

MUNIZ, V. Reflex: Vik Muniz de A a Z. São Paulo: Cosac, 2007.

NEEFS, J. La prévision de l'œuvre. Genesis, n. 6, p. 107-116, 1994. 
OSTROWER, F. Criatividade e processos de criação. 25. ed. Petrópolis: Vozes, 2010.

PANICHI, E. R. P.; CONTANI, M. Pedro Nava e a construção do texto. Londrina: EDUEL; São Paulo: Ateliê Editorial, 2003.

REYNAUD, M. J. Genesis: a outra dimensão da escrita. Revista da Faculdade de Letras: Línguas e Literatura, Porto, s. 2, v. 10, p. 231-234, 1993.

SALLES, C. A. Gesto inacabado: processo de criação artística. São Paulo: FAPESP; Annablume, 1998.

SALLES, C. A. Crítica genética: uma (nova) introdução; fundamentos dos estudos genéticos sobre o processo de criação artística. 2. ed. São Paulo: EDUC, 2000.

SALLES, C. A. Crítica genética e semiótica: uma interface possível. In: ZULAR, R. (Org.). Criação em processo: ensaios de crítica genética. São Paulo: Iluminuras, 2002. p. 177-202.

SALLES, C. A. Arquivos de criação: arte e curadoria. Vinhedo: Horizonte, 2010.

WILLEMART, P. Os processos de criação na escritura, na arte e na psicanálise. Universo da criação literária. São Paulo: Edusp, 1993.

WILLEMART, P. Como se constitui a escritura literária. In: ZULAR, R. (Org.). Criação em processo: ensaios de crítica genética. São Paulo: Iluminuras, 2002. p. 73-94.

WILLEMART, P. Os processos de criação na escritura, na arte e na psicanálise. São Paulo: Perspectiva, 2009.

Enviado em: 05/10/2016

Aceito em: 14/12/2016 